www.jmscr.igmpublication.org

Index Copernicus Value: 79.54

ISSN (e)-2347-176x ISSN (p) 2455-0450

crossref DOI: https://dx.doi.org/10.18535/jmscr/v7i6.83

$\underline{\text { Research Article }}$

\title{
Accuracy of intra-operative imprint cytology in breast tumours and lymph node swellings: Can it be a useful alternate to Frozen section
}

\author{
Authors \\ Dr Ravindran Chirukandath ${ }^{1} *$, Dr Venita Juliet Noronha ${ }^{2}$, Dr Remani.K ${ }^{3}$, \\ Dr Sarath Krishnan ${ }^{4}$ \\ ${ }^{1,2,4}$ Department of General Surgery, Government Medical College, Thrissur, Kerala State, India \\ ${ }^{3}$ Department of Pathology, Government Medical College, Thrissur, Kerala State, India \\ *Corresponding Author \\ Dr Ravindran Chirukandath
}

Additional Professor of Surgery, Department of General Surgery, Government Medical College, Medical

College P.O., Thrissur, Kerala State, India, Pin code- 680596

\begin{abstract}
Background: In the present clinical scenario, breast lumps and lymph nodes swellings are one of the most common pathologies we deal with in our surgical outpatients. With the present increasing rate of malignancies, even benign and innocent looking lumps must be treated with suspicion and care. And hence we need an investigative procedure which is accurate, simple and less time consuming and cost effective. Imprint cytology is a good procedure to assess the diagnosis of lesions and is comparable to the final histopathology report ${ }^{(1)}$. It is indeed helpful to avoid a second surgery in cases where a wide excision is required because the report comes within 10-15 minutes. This in turn helps surgeons to plan further treatment

To know the accuracy of imprint smears in breast and lymph nodes in diagnosing lesions this study was conducted and to statistically compare with routine histopathology in order to assess sensitivity and specificity of imprint diagnosis and Compare statistically it with routine histopathology tests to know sensitivity, specificity, positive predictive value and negative predictive value.

160 patients from Govt. Medical College, Thrissur, Kerala, India with breast lumps \& lymphadenitis requiring excision biopsy were included in the study. It was found that In diagnosis of breast Tumours the Result of intra-operative imprint cytology had a Sensitivity $=95.60 \%$; Specificity $=100 \%$; Predictive value - +ve100\% \& -ve 97\% in Breast lumps .In diagnosis of Lymph Node Lesions the Predictive value for metastatic carcinoma Sensitivity = 100\%; Specificity $=100 \%$; Predictive value $-+v e 100 \% \&-v e 100 \%$ and Predictive value for metastatic carcinoma with a Sensitivity $=77.7 \%$; Specificity $=100 \%$; Predictive value - +ve $100 \%$ \& -ve $91.3 \%$. Further research in this field is planned to understand the efficacy To assess the accuracy of imprint cytology in evaluating lumpectomy margins.
\end{abstract}

Keywords: Intra-operative Imprint Cytology. 


\section{Introduction}

In the present clinical scenario, breast lumps and lymph nodes swellings are one of the most common pathologies we deal with in most Outpatient surgical department. With the present increasing rate of malignancies, even benign and innocent looking lumps must be treated with suspicion and care. And hence we need an investigative procedure which is accurate, simple and less time consuming and cost effective.

Routinely, in our hospital settings, breast lumps and lymph nodes are subjected to TRIPLE ASSESSMENT; i.e. clinical diagnosis, FNAC and mammography and USG. The first two are an indispensable tool and we need a new procedure that overcomes the limitations of FNAC ${ }^{(2)}$. Fine Needle Aspiration Cytology is a widely accepted procedure because of its convenient application, OP procedure, cost effective and rapid results. But it has its own drawbacks because the so-called rapid results often read "suspicious, but not confirmatory". Moreover, the diagnosis of the lesion depends upon the aspirated material which may not be representative of the true lesion and this may result in a false positive diagnosis.

Tru cut Biopsy is superior to FNAC because we are getting ample tissue material for cytology. But there are again a few disadvantages. It's more painful and more than that if the lesion is quite close to the skin or contained in a small breast, then trucut biopsy is not advisable due to the required throw of the needles. It's also contraindicated where lesions are quite few and while scattered.

Another solution is Frozen Section biopsy which implies specialized equipment which may not be available everywhere as well as requires an experienced pathologist to interpret. There are also available these days latest techniques such as flow cytometer, tumour markers but these are very expensive and may not be available to the everyday patient.

As an alternative we look into Imprint Cytology, also known as Touch smear preparation ${ }^{(3)}$. Here we excise the lesion and make an imprint of it on a glass slide. Rapid H \& E is done and the result read in $10 \mathrm{~min}$. In the case of lymph nodes, we can excise for various swellings looking for metastasis and in the case of carcinoma breast, only the sentinel lymph nodes need to be removed avoiding removal of axillary lymph nodes and prevent complications such as lymphoedema. Hence by this methodology we have a rapid, simple and absolute no requirement of any specialized equipment's.

Hence the present study is taken to see how accurate these imprint smears of breast and lymph nodes comparing with other parameters such as clinical diagnosis, FNAC and final histopathology.

\section{Materials and Methods}

This study was conducted at Government Medical College, Thrissur, Kerala, India in 121 patients. All patients with breast lumps and lymphadenitis requiring excision biopsy were taken into the study and All selected patients had pre- operative FNAC for initial work up for indication for surgery. Cases of Acute mastitis, Acute lymphadenitis Un-cooperative patients in which follow up is not possible was excluded in the study.

Institutional Ethical Committee clearance was obtained. All patients coming to OP with history of breast lump or lymph node swelling is first subjected to thorough history taking and clinical examination. Then a pre- operative FNAC is done. A detailed consent is obtained and the need for excision biopsy is explained. The consented patients are then posted for excision biopsy. Once tumour is excised, it is sectioned, and its macroscopic features are noted for any foci of suspicion. Cut surface is pressed on a clean slide and fixed $90 \%$ ethanol and sent to cytopathologic along with its clinical details. In the laboratory, smears are subjected to Rapid $\mathrm{H} \&$ E. The staining process takes 5 minutes and to read the slide another 5 minutes. Once the diagnosis is made, it's compared to the final Histopathology report later. 


\section{Results}

Imprint cytology was done in 41 benign breast lumps and 20 malignant suspicious lumps Of the 61 breast lumps sampled, 21 showed malignant changes and the rest 40 were benign as per the histopathology report. Of this 21 malignant tumours, only 1 was incorrectly identified. It came out as benign lesion but actually it was invasive ductal carcinoma - grade III. The sensitivity rate in picking up malignancy was found to be $95.23 \%$

Table 1: BREAST LUMPS (Results of intraoperative imprint smears)

\begin{tabular}{|l|c|}
\hline DIAGNOSIS & No. of patients \\
\hline Benign & $\mathbf{4 1}$ (1 false negative) \\
\hline Malignant & $\mathbf{2 0}$ \\
\hline
\end{tabular}

Table 2: Result of final Histopathology report )

\begin{tabular}{|l|c|}
\hline DIAGNOSIS & CASES \\
\hline Fibroadenoma & $\mathbf{2 4}$ \\
\hline Fibrocystic disease & $\mathbf{8}$ \\
\hline Gynaecomastia & $\mathbf{4}$ \\
\hline Granulomatous mastitis & $\mathbf{2}$ \\
\hline Phylloides tumour & $\mathbf{2}$ \\
\hline Carcinoma( all types) & $\mathbf{2 1}$ \\
\hline TOTAL & 61 \\
\hline
\end{tabular}

Table 3

\begin{tabular}{|l|l|l|}
\hline $\begin{array}{l}\text { TEST } \\
\text { RESULT }\end{array}$ & Malignant & Benign \\
\hline Positive & 20 (a)True positive & 0(b)False positive \\
\hline negative & 1(c)False negative & 40 (d)True negative \\
\hline
\end{tabular}

Sensitivity $=a / a+c * 100=95.23 \%$

Positive predictive value $=\mathrm{a} / \mathrm{a}+\mathrm{b} * 100=100 \%$

Specificity $=\mathrm{d} / \mathrm{d}+\mathrm{b} * 100=100 \%$

Negative predictive value $=d / d+c * 100=97.56 \%$
The results of imprint smears on 39 lymph nodes is as given in tables 4,5,6 and 7. through the imprint smear preparation, we got 18lymphnodes showing reactive hyperplasia, 7 showing granuloma formation, 7 showing lymphoma (both Hodgkin's and Non- Hodgkin's Lymphoma) and 7 showing metastatic carcinoma all of which were secondaries from squamous cell carcinoma. This means that out of 39 samples, 2 were negative $6 \%$ which is well within reasonable limits.

Table 4: Results of intra-operative imprint smears in Lymph Nodes

\begin{tabular}{|l|c|c|}
\hline DIAGNOSIS & TOTAL & Final Histopathology \\
\hline Reactive change & 18 & 16 \\
\hline Granuloma & 7 & 7 \\
\hline Lymphoma & 7 & 9 \\
\hline $\begin{array}{l}\text { Metastatic } \\
\text { carcinoma }\end{array}$ & 7 & 7 \\
\hline
\end{tabular}

The sensitivity of imprint smear in detecting metastatic carcinoma was $100 \%$ but in detecting lymphomas it was only $77 \%$. Lymph nodes were examined from cervical, axillary and inguinal region. Cervical Lymph nodes were preferred site for reactive change and granuloma formation while for lymphoma, preferred site was axilla

Table 5: predictive value for metastatic carcinoma and Lymphoma

\begin{tabular}{|l|c|c|c|c|c|c|}
\hline TEST RESULT & Metastasis & Others & Sensitivity & Specifity & $\begin{array}{c}\text { Positive } \\
\text { Predictive } \\
\text { value }\end{array}$ & $\begin{array}{c}\text { Negative } \\
\text { Predictive } \\
\text { Value }\end{array}$ \\
\hline Metastatic Carcinoma & 7 & 0 & $100 \%$ & $100 \%$ & $100 \%$ & $100 \%$ \\
\hline Positive & 0 & 32 & & & \\
\hline negative & 7 & 0 & $\mathbf{7 7 . 7 2 \%}$ & $\mathbf{1 0 0 \%}$ & $\mathbf{1 0 0 \%}$ & $\mathbf{9 3 . 7 5 \%}$ \\
\hline Lymphoma (NHL and HL) & 2 & 30 & & & & \\
\hline Positive & 7 &
\end{tabular}


Fig 1 Imprint smear-non hodgkin's lymphoma

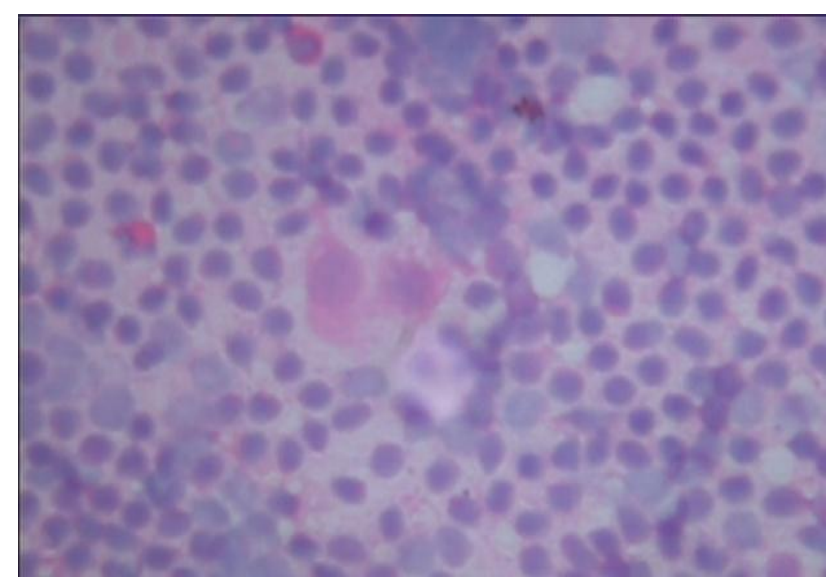

Fig 2 - Imprint smear- fibroadenoma breast (low power view)

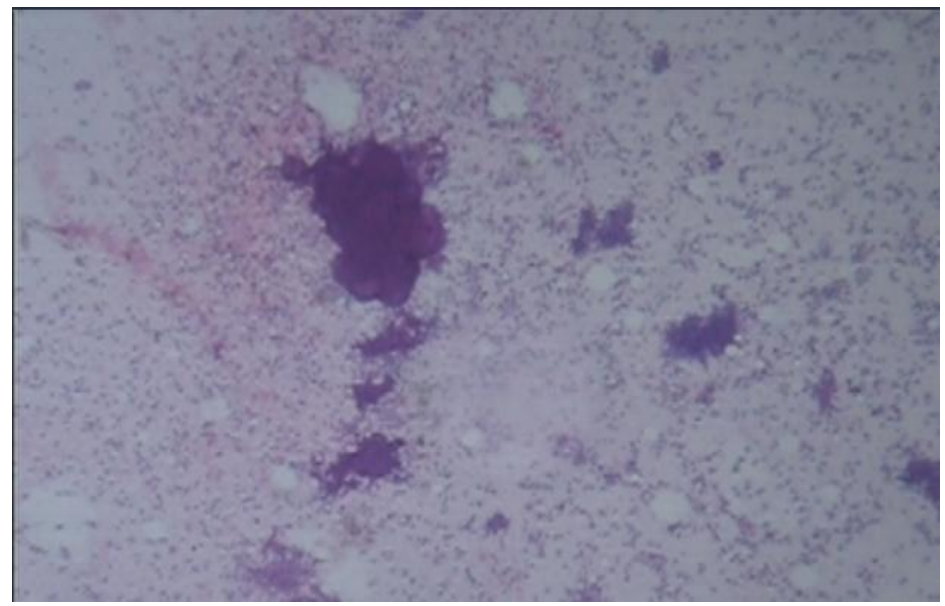

\section{Discussion}

The fact that imprint smear seems to be fastest and easiest way of diagnosing lesions seems to have good impact in the surgical field which is still causing more and more research into it. In our study, we have sampled 110 patients, 61 breast tumors and 39 lymph nodes. Breast tumors have reported a sensitivity of $95.23 \%$ and a specificity of $100 \%$. This is quite comparable to other studies. ${ }^{(5,6,7,8)}$

\begin{tabular}{|l|c|c|c|c|c|c|c|c|}
\hline STUDY & Year & N & FP & FN & Sensitivity & Specificity & PPV & NPV \\
\hline Cox & 1991 & 114 & 3 & 0 & 100 & 97 & 100 & $\mathbf{8 8}$ \\
\hline Klimberg & 1998 & 83 & 0 & 0 & 100 & 100 & 100 & $\mathbf{1 0 0}$ \\
\hline Creager & 2002 & 137 & 15 & 20 & 80 & 85 & 40 & $\mathbf{9 7}$ \\
\hline Hirgeoudar & $\mathbf{2 0 0 6}$ & $\mathbf{4 0}$ & $\mathbf{0}$ & $\mathbf{1}$ & $\mathbf{9 5 . 2}$ & $\mathbf{1 0 0}$ & $\mathbf{1 0 0}$ & $\mathbf{9 5}$ \\
\hline
\end{tabular}

The sensitivity of detecting malignant tumours is $95.23 \%$. This is a little high but may be of the fact that only few samples had malignant changes. The ongoing study in the department may bring more light into this soon comparing larger numbers of specimen. Moreover, it is to be stressed that imprints should always be interpreted in the light of gross specimen. If the clinical and gross specimen shows suspicion, then a negative imprint should be considered as doubtful.
Quite another reason that has to be put forward is that there can be technical as well as interpretative errors. Technical error usually occurs while making the smear. We had to discard the initial 2 smear because the technique was improper. The specimen has to be cut neatly and has to be pressed firmly on to the slide. Specimen should not slide over the glass slide because it will alter the morphology of the cells. But this usually can be avoided by gaining experience. Preparing 4- 5 
slides is enough to know the technique of developing a good smear. Interpretative errors occur in well differentiated tumors where neoplastic changes are not much clear. In such cases, if it $\mathrm{s}$ a mastectomy specimen we can take imprint smears of lymph nodes as well. This will not take much time and should be done simultaneously or after $10 \mathrm{~min}$ if the imprint comes negative in such doubtful cases.

However in our study, imprint smear had 2 false negative in final diagnosis of benign lesion. In one case patient had clinically a giant fibroadenoma (FNAC had the same diagnosis as well) the lesion was around $15 \mathrm{~cm}$ and on the backup of the clinical diagnosis only a small smear was made which didn't carry the specific diagnostic cellular morphology. The final HP diagnosis came out to be borderline Phyllodes tumour. This points a finger to the fact that in larger sized tumors and specimens the accuracy may be limited due to technical reasons of imprint making and more light needs to be thrown regarding preparation of smears in that context. However this is of not much relevance because our final diagnosis is to detect whether the lesion harbours atypical changes because of the relevance of evaluating margin status and avoiding a re- excision surgery. In the case of lymph nodes also we got imprints corresponding to metastatic carcinoma. All 7 were secondaries from squamous cell carcinoma. The sensitivity, specificity, positive and negative predictive value were $100 \%$. However lymphomas were not detected rapidly. Sensitivity for detection of lymphomas was only $77 \%$.in one case of lymphoma the specimen obtained was axillary lymph nodes. Whole specimen was clumped and gross morphology was quite deviated from normal. Admixed with soft tissue it was quite difficult to ascertain which was lymph node matter and that could be the reason of false negative seen.

A study by Suen et al showed the diagnosis of signet cell carcinoma in lymph node can be mistaken sinus histiocytosis on frozen section but comes excellently on imprint smear. However we failed to get hold of such a specimen. About the smears which was prepared it was par excellence. The whole lesion was well representable and hence gave excellent cytological clarity. It was far better than FNAC smears. Moreover, the stain used -Rapid $\mathrm{H}$ and $\mathrm{E}$ was equally matched.

\section{Conclusion}

Imprints were made on 110 freshly excised surgical specimens of breast and lymph node swellings. Rapid H \& E was performed and the resultant smears gave excellent cytological morphology and was more impressive. The rapidity and speed with which smears can be prepared and read should be taken to full advantage by the surgeons. Diagnostic accuracy increases when used together with Final Paraffin Section.

In this study Breast swellings have reported a sensitivity of $95.6 \%$ and a specificity of $100 \%$. The sensitivity, specificity, positive and negative predictive values were $100 \%$. However lymphomas were not detected rapidly. Sensitivity for detection of lymphomas was only $77 \%$ in one case of lymphoma.

So we feel that Imprint cytology is an effective alternative for quick and accurate diagnosis of Breast and Lymph node swellings. But more cases needs to be done for refining the technique and identify the margins of the lesions in breast cancer and other tumors. Its role in Lymphnode swellings are also promising but the role in Lymphomas needs refining. There is always a further scope for continuous research in this field and spreading the indications to various other swellings.

\section{Acknowledgements}

Sincere thanks to the Department of Pathology and Department of general surgery for facilitating the study

\section{Declarations}

Funding: SBMR

Conflict of interest: Nil

Ethical approval: Obtained 


\section{References}

1. Hiregoudar AD, Godhi AS, Malur PR, Gogeri BV, Metgud SC. Accuracy ofintraoperative imprint smears in breast tumours: A study of 40 caseswith review of literature. Indian J Surg2006;68:302-5

2. Dudgeon LC, Patrick CV. A new method for the rapid microscopical diagnosis of tumours: With an account of 200 cases so examined. Br JSurg1927;25:250

3. Cox CE, Ku NN, Reintgen DS, Greenberg HM, Nicosia SV, Wangensteen S. Touch preparation cytology of breast lumpectomy margins with histologic correlation. Arch Surg1991;126:490-3. [PUBMED]

4. Suen KC, Wood WS, Syed AA, Quenville NF, Clement PB. Role of imprint cytology in intraoperative diagnosis: value and limitations. Journal of Clinical Pathology 197831, 328-337

5. Tribe CR. A comparison of rapid methods including imprint cytodiagnosis for the diagnosis of breast umours. Journal of Clinical PATHOLOGY 1973: 26:273-277

6. Creager AJ, Shaw JA, Young PR, Geisinger KR. Intra-operative evaluation of lumpectomy margins by imprint cytology with histologic correlation: A community hospital experience. Arch Pathol Lab Med2002;126:846-8. [PUBMED] [FULLTEXT]

7. Klimberg VS, Harms S, Korourian S. Assessing margin status. Surg Oncol 1999;8:77-84. [PUBMED] [FULLTEXT]

8. Saarela AO, Paloneva TK, Rissanen TJ, Kiviniemi HO. Determinants of positive histologic margins and residual tumour after lumpectomy for early breast cancer: A prospective study with special reference to touch preparation cytology. Surg Oncol 1997;66:248-53.

[PUBMED]
9. Shidham V, Gupta D, Galindo LM, Haber M, Grotkowski C, Edmonds P,et al . Intraoperative scrape cytology: Comparison with frozensections, using receiver operating characteristic (ROC) curve. DiagnCytopathol2000;23:134-9.

10. Creager AJ, Geisinger KR, Perrier ND, Shen P, Shaw JA, Young PR,et al . Intraoperative imprint cytologic evaluation of sentinel lymphnodes for lobular carcinoma of the breast. Ann Surg 2004;239:61

11. Cendan JC, Coco D, Copeland EM 3rd. Accuracy of intraoperative frozen section analysis of breast cancer lumpectomy bed margins. J Am Coll Surg2005;201:194-8. [PUBMED] [FULLTEXT]

12. Dutta SK, Chattopadhyaya A, Roy S. Evaluation of fine needleaspiration and imprint cytology in the early diagnosis of breast lesions with histo-pathological correlation. J Indian Med Asso c2001;99:421-3.

\section{[FULLTEXT]}

